\title{
Influence of 'bouchot' mussel culture on the benthic environment in a dynamic intertidal system
}

\author{
Cindy Grant ${ }^{1}$, Philippe Archambault ${ }^{1, *}$, Frédéric Olivier $^{1,2}$, \\ Christopher W. McKindsey ${ }^{3}$ \\ ${ }^{1}$ Laboratoire d'écologie benthique, Institut des sciences de la mer, Université du Québec à Rimouski, 310 Allée des Ursulines, \\ CP 3300, Rimouski, Québec G5L 3A1, Canada \\ ${ }^{2}$ Muséum National d'Histoire Naturelle, Département Milieux et Peuplements Aquatiques, Unité Mixte de Recherche, \\ BOREA CNRS/P6/MNHN/IRD, 38 rue du Port Blanc, 35800 Dinard, France \\ ${ }^{3}$ Ocean and Environmental Sciences Division, Maurice-Lamontagne Institute, Fisheries and Oceans Canada, PO Box 1000, \\ Mont Joli, Québec G5H 3Z4, Canada
}

\begin{abstract}
The present study examines the influence of mussel aquaculture structures (bouchots) in the intertidal zone of the Chausey Archipelago (Normandy, France) where strong tidal currents are predicted to disperse biodeposits. Six sites were sampled to determine the spatial variability of organic matter content, sediment grain size, and benthic infaunal community characteristics. The influence of bouchots on the benthic environment was evident at both the mesoscale (i.e. km-scale, between farm and reference sites) and small-scale (i.e. m-scale, spatial structure within farms but not reference sites). This influence was also apparent for sediment grain size distribution and most metrics of macrobenthic community structure, but not for sediment organic matter. Mussel culture structures likely modify natural flow patterns within farm sites, which increases shear stress around individual bouchots, thereby increasing the heterogeneity of benthic communities, altering the dominance of particular species within farms and differentiating them from reference sites.
\end{abstract}

KEY WORDS: Mussel aquaculture - Bouchot · Benthic community $\cdot$ Coarse sediment $\cdot$ Intertidal · Dynamic system $\cdot$ Chausey Archipelago

\section{INTRODUCTION}

Increasing anthropogenic pressure in coastal areas is of concern for the conservation and management of certain habitats. Numerous coastal landscapes have been modified by a variety of human activities, including fishing and aquaculture. Many studies have highlighted the influence of aquaculture activities on coastal environments, especially the effect of fish and bivalve farming (Black 2001, Holmer et al. 2008). An understanding of the extent of any effects that aquaculture may have on the environment is needed for conservation purposes and because the long-term sustainability of the industry depends on the health of the natural ecosystem in which aquaculture is practiced.

Bivalve culture areas can be extensive, covering many square kilometres, and the introduction of large densities of bivalves in a specific area may bring about important changes to coastal ecosystems. The great filtration capacity of bivalves may deplete phytoplankton, zooplankton and seston in the water column (Dame 1996, Lehane \& Davenport 2004, 2006, Grant et al. 2008). In addition, biodeposition from farmed bivalves increases sedimentation rates locally and may result in organic enrichment of the sea bottom (Haven \& Morales-Alamo 1966, Callier et al. 2006, Cranford et al. 2009). The physical structure of 
aquaculture installations may also promote sedimentation by reducing current flow at various spatial scales (Nikodic 1981, Sornin 1981). Such increased sedimentation has often been shown to impact benthic communities as predicted by the empirical succession model outlined by Pearson \& Rosenberg (1978), whereby organic loading decreases species richness and increases the abundance of opportunistic species, such as certain families of polychaetes (e.g. Chamberlain et al. 2001, Hartstein \& Rowden 2004). Conversely, some studies have also shown either neutral (Crawford et al. 2003) or positive effects of bivalve aquaculture on infaunal diversity (Callier et al. 2009) and macrobenthic mobile species (Inglis \& Gust 2003, Clynick et al. 2008).

Variation among studies on mussel aquaculture effects on the benthic environment may be explained in part by differences among culture sites in terms of hydrodynamics, topography, enrichment background, and grain size (Sarà et al. 2006). Generally, organic enrichment due to mussel aquaculture will be greater at sites that are naturally depositional and where hydrodynamic processes are weak (Chamberlain et al. 2001, Hartstein \& Rowden 2004, Cranford et al. 2009). Conversely, studies have shown that farms established in off-shore locations that are dominated by strong hydrodynamic regimes have less of an effect on the bottom because biodeposits are better dispersed, thus reducing local organic enrichment (Hartstein \& Rowden 2004, Fabi et al. 2009).

Hydrodynamic processes are also considered to be one of the most important factors determining the spatial distribution of sediment types and consequently the associated benthic organisms (Jumars \& Nowell 1984, Miller \& Sternberg 1988). According to Grebmeier et al. (1989), sediment grain size is the major factor determining biodiversity and the dominant benthic taxa whereas organic carbon, as food, influences biomass. Sediment grain size distribution is an indicator of hydrodynamic transport and sedimentation, both of which influence benthic fauna in an area (Grebmeier et al. 2006). In general, coarse intertidal sediments are dominated by taxa that have adapted to such unstable substrata (Gray \& Elliott 2009), often carnivores and suspension feeders, whereas fine organically rich sediments tend to contain more burrowing deposit feeders (Martin et al. 2005). Although coarse sediments were previously considered to be poorly reactive because of their typically low organic carbon content, recent studies have demonstrated that biogeochemical processes in these sediments may be as intense as those in muddy environments due to great pore-water circulation (Huettel \& Rusch 2000).
Given this, biodeposition-related effects of bivalve culture are predicted to be generally limited in areas dominated by strong hydrodynamic regimes. However, this prediction has been evaluated through studies that have been, for the most part, done in relatively organically rich soft sediment environments (see McKindsey et al. 2011). Little is known about the influence of bivalve aquaculture installations on benthic infaunal communities in systems that have naturally low levels of organic matter and composed of coarse sediments or in highly dynamic intertidal systems. To address this knowledge gap, the present work presents a study of the influence of mussel culture on benthic communities in such a system.

This study evaluated the small-scale (within farm) and meso-scale (km-scale) influences of intertidal mussel aquaculture on the benthic environment of the Chausey Archipelago (Normandy, France), a very dynamic system of great natural heritage value. Specifically, the present observational study examined how mussel culture influences (1) the sedimentary environment and (2) benthic infaunal characteristics and communities. We hypothesized that mussel aquaculture structures influence small-scale sediment dynamics and thereby influence the abundance, diversity, and structure of benthic infaunal communities in their immediate vicinity. To better evaluate the generality of the observed patterns in the study area, this work was replicated at 3 mussel farm sites and 3 reference sites in the eastern part of the Chausey Archipelago.

\section{MATERIALS AND METHODS}

\section{Study site}

The study was done in the Chausey Archipelago (ca. $11 \times 5 \mathrm{~km} ; 5100 \mathrm{ha}$ ) located in the NormandBreton Gulf, France (Fig. 1). This archipelago is composed of 50 to 300 islands depending on the tidal state and is influenced by a semi-diurnal mega-tidal regime (tidal range up to $14 \mathrm{~m}$ during the largest spring tides) that creates large intertidal areas (1995 ha), including 1388 ha of tidal flats (Godet 2008). The Chausey Archipelago is an area of great natural heritage value and is protected by various conservation measures, including designation as a 'Natura 2000 site' by the European Network (www. natura2000.fr) in 2005. Mussel (Mytilus edulis) aquaculture structures in Chausey are wooden stakes called bouchots (Fig. 2) that are driven into the 


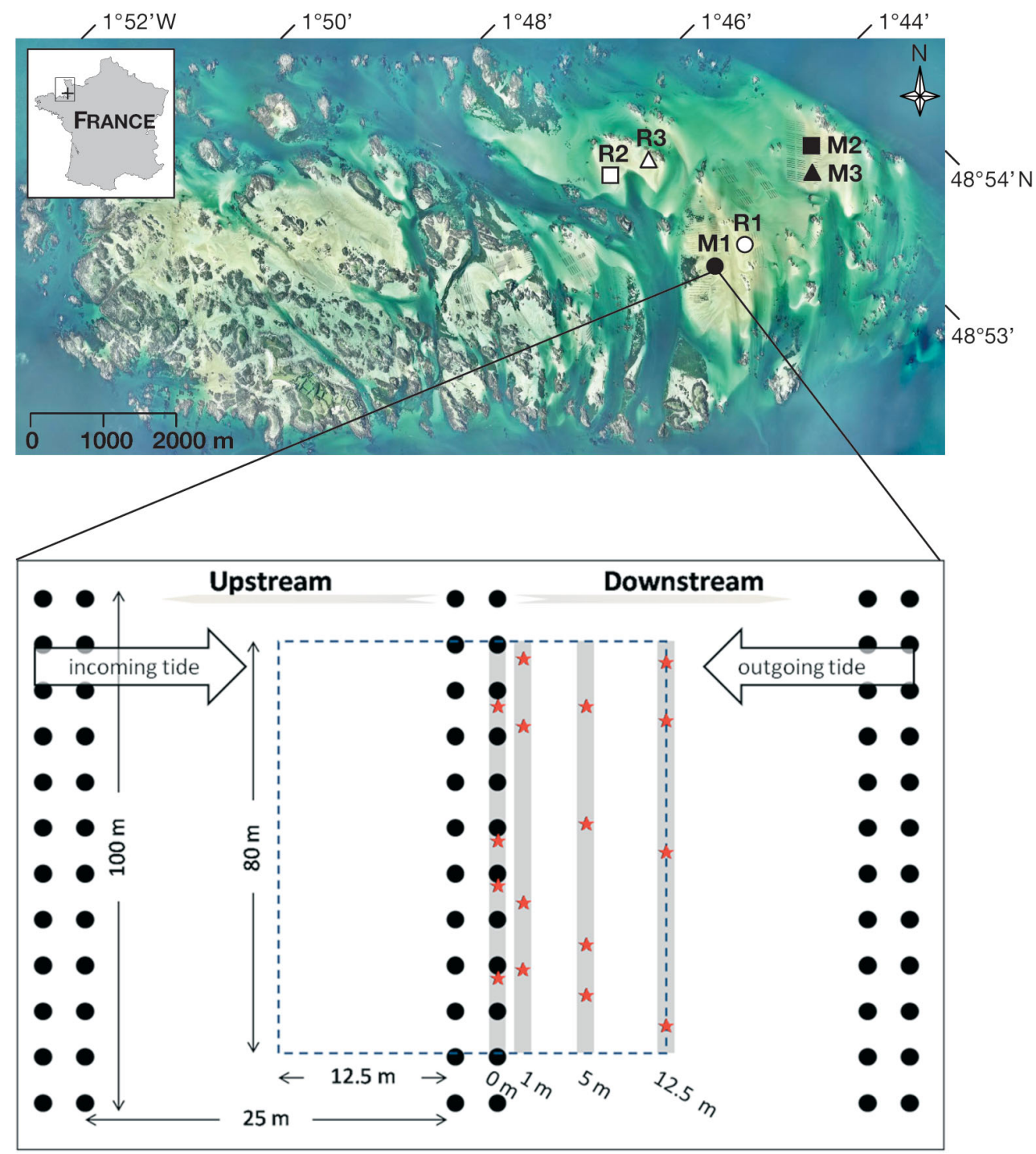

Fig. 1. Location of the study site (+ in top inset) in the Chausey Archipelago (France) and sampling design used at both mussel

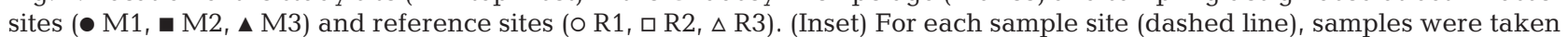
along transects (gray lines) at 4 distances $(0,1,5$ and $12.5 \mathrm{~m}$ ) upstream and downstream and parallel to paired bouchot lines $(\bullet)$. At each distance, samples $(\star)$ were taken at 4 randomly chosen positions $\left(\mathrm{N}_{\text {total }}=192\right)$. At reference sites, PVC stakes were used to represent bouchots. The number of black circles shown under-represents the actual number of bouchots used. Photo credit: J. Fournier (CNRS) and P. Talec (DIREN Basse-Normandie)

ground, leaving about $3 \mathrm{~m}$ exposed, in low extended areas and arranged in ca. $100 \mathrm{~m}$ rows with ca. $1 \mathrm{~m}$ separating individual bouchots. In this system, blue mussels recruit to ropes which are placed in the field for this purpose. Once recruitment occurs, lengths of these ropes with spats are then wrapped around bouchots, with the growing mussels becoming attached to bouchots over time. Paired rows of bouchots, separated by ca. $2 \mathrm{~m}$, are separated from other paired rows by ca. $25 \mathrm{~m}$ (Fig. 1). Such installations cover a total surface area of 70 ha and have been in operation for about $40 \mathrm{yr}$, producing approximately $2000 \mathrm{t}$ of mussels annually (Godet 2008).

\section{Field sampling and laboratory methods}

Sampling was done at 6 intertidal sites, including 3 mussel farm sites and 3 reference sites, from May 14 to 19, 2007 (Fig. 1). All sites are at about the same level in the intertidal zone and are located in the Glycymeris glycymeris dominated coarse sediment habitat (Godet 2008). In order to reduce edge effects, as shown by Sornin (1981), sampling was done only within the $80 \mathrm{~m}$ in the centre of rows of paired mussel lines. Upstream and downstream positions were defined relative to the main tidal currents and swells and were located north and south of lines of bou- 


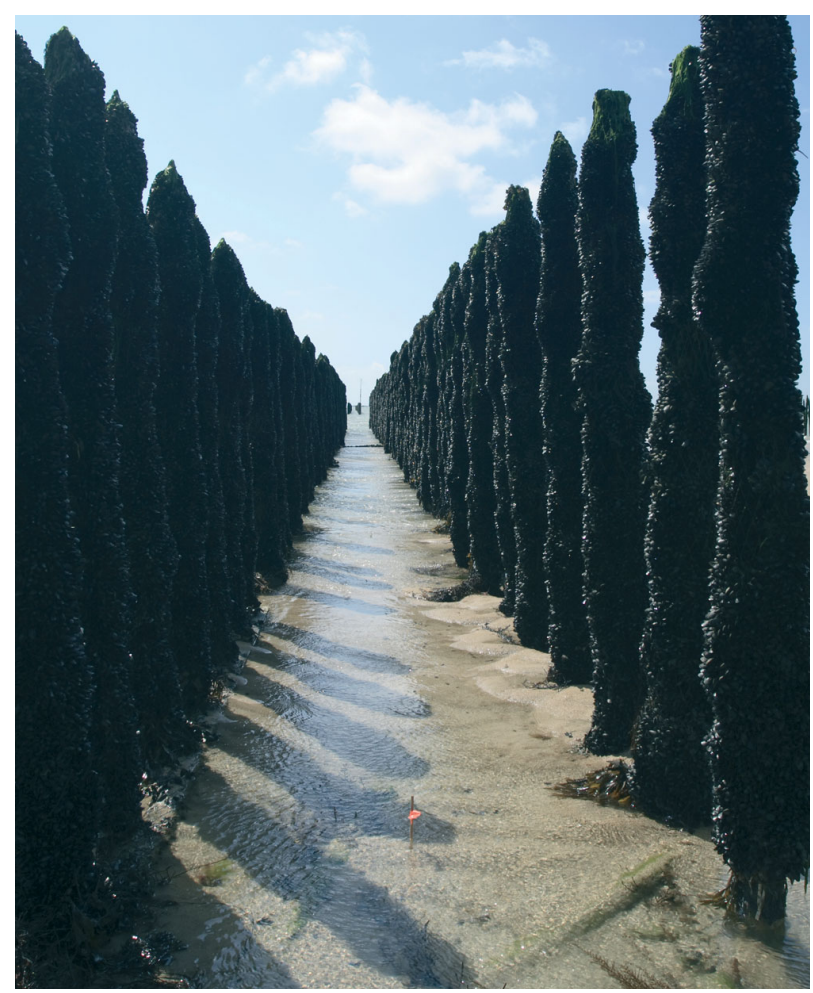

Fig. 2. Mytilus edulis. Mussel culture on bouchots during low tide in the Chausey Archipelago, France

chots, respectively (Fig. 1). For each site within farmed areas (M1, M2, M3), both upstream and downstream samples were taken at 4 distances away from centrally-located paired lines of bouchots: directly along them $(0 \mathrm{~m})$ and at 1,5 , and $12.5 \mathrm{~m}$ from the lines $\left(n=4\right.$ replicates per distance, $\mathrm{N}_{\text {total }}=192$, Fig. 1). The same sampling design was used at randomly selected reference sites (R1, R2, R3) to allow comparisons of small-scale spatial patterns. At reference sites, samples were taken in the same manner as in the farm sites but around imaginary bouchot lines established in random locations while respecting the orientation of main currents.

For sediment analysis, sub-surface sediment samples were collected with a syringe $(3 \mathrm{~cm}$ diameter, $5 \mathrm{~cm}$ depth) to characterize sediment texture and organic content at each sample location $(\mathrm{n}=4)$. Sediment samples were dried at $70^{\circ} \mathrm{C}$ for $24 \mathrm{~h}$ and grain size ( 0.25 phi precision) was determined using a dry sieve; results are expressed as percentages of the total sample weight. The percent organic content of the sediments was calculated as the dry material weight loss after combustion at $550^{\circ} \mathrm{C}$ until a constant weight was obtained (about $2 \mathrm{~h}$ ). Organic content was determined for 4 sites (M1, M2, R1, R3; $\mathrm{N}_{\text {total }}=128$ ).
Samples for infauna analysis were collected using a corer (16 cm diameter, $15 \mathrm{~cm}$ depth, $\mathrm{n}=4)$. Benthic samples were sieved through a $2 \mathrm{~mm}$ circular mesh. Although the use of a $2 \mathrm{~mm}$ mesh will clearly underestimate what is typically considered to be infauna (typically those organisms retained on a $500 \mu \mathrm{m}$ or $1 \mathrm{~mm}$ mesh), the use of a smaller mesh size with the coarse sediment collected at the study site would have necessitated a greatly reduced sampling effort and thus a weaker statistical design. Moreover, many studies have shown that larger mesh sizes retain the greater proportion of biomass of infaunal samples, and broad patterns with respect to community structure and relative diversity remain valid when only larger organisms are considered (e.g. James et al. 1995, Callaway et al. 2002, Couto et al. 2010). Retained material was preserved in $5 \%$ buffered formalin. Macrofauna were identified to the lowest taxonomic level possible and their abundance recorded. Colonial organisms (hydrozoans and bryozoans), which were uncommon, were excluded from analyses because they could not be enumerated.

\section{Statistical methods}

Sediment parameters including mean grain size, sorting (standard deviation), and skewness (symmetry or preferential spread to one side of the average) were calculated to identify trends in sediment grain size. These parameters were obtained by the geometric method of moments using Gradistats version 4.1 (Blott \& Pye 2001). Univariate macrofaunal indices calculated include total abundance $(\mathrm{N}$, ind. $\left.\mathrm{m}^{-2}\right)$, number of taxa $(S)$, Pielou's evenness index $\left(J^{\prime}\right)$, Shannon-Wiener's diversity index $\left(H^{\prime}\right.$, base e), average taxonomic distinctness $\left(\Delta^{+}\right)$and variation in taxonomic distinctness $\left(\Lambda^{+}\right)$. The latter 2 measures estimate the average distance between 2 randomly chosen organisms through Linnean taxonomy and determined using presence/absence data. All univariate ecological indicators were calculated using Primer version 6 (Clarke \& Warwick 2001, Clarke \& Gorley 2006). The ecological quality of benthic communities was evaluated using the AZTI Marine Biotic Index (AMBI) (Borja et al. 2000) using AMBI 4.0 (available at www.azti.es) and following the guidelines of Borja \& Muxika (2005). When taxa could not be assigned to an ecological group, they were attributed according to the tolerance of their genus or other closest taxonomic group. 
Univariate variables (sediment organic content, mean grain size, sorting, skewness, $\mathrm{N}, S, J^{\prime}, H^{\prime}, \Delta^{+}$, $\left.\Lambda^{+}, \mathrm{AMBI}\right)$ were compared using 4 factor partlynested analyses of variance (ANOVA). Factors included treatment (fixed with 2 levels; mussel and reference), site (random with 3 levels; 3 mussel sites-M1, M2, M3 - and 3 reference sites-R1, R2, R3 - and nested in treatment), orientation (fixed with 2 levels; upstream and downstream), and distance (fixed with 4 levels; 0, 1, 5 and $12.5 \mathrm{~m}$ ), with $\mathrm{n}=4$ observations per combination of factor levels. Power analyses (Underwood 1997) were done to determine the adequate number of replicates prior to sampling. Assumptions of homoscedasticity and normality were verified visually by the distribution of residuals as suggested by Quinn \& Keough (2002), and data were transformed when necessary. When transformations could not normalize data or remove heteroscedasticity, analyses were done on untransformed data as ANOVA is robust to departures from such assumptions, particularly with balanced designs and when there are many independent estimates of sample variance (Underwood 1997). A posteriori comparisons were made using Tukey's test.

Multivariate analysis of benthic community structure, including a posteriori pair-wise comparisons, were done using the same statistical design with a distance-based permutational multivariate analysis of variance (PERMANOVA with 9999 permutations) (Anderson 2001, Anderson et al. 2008). Benthic community analyses were done using both untransformed and presence/absence-transformed data. These 2 extreme transformations were done to provide contrasting views of community structure with the first being most influenced by the most abundant species and the second by the number of species observed. Taxa with a single occurrence were excluded from multivariate analyses to reduce noise in the data set (Clarke \& Warwick 1994). Variation in benthic community structure was visualized using non-metric multidimensional scaling (nMDS) ordination based on Bray-Curtis dissimilarities in PRIMER (Clarke 1993, Clarke \& Gorley 2006). The percentage similarity and the identification of taxa that contributed most to the total dissimilarity between groups were calculated using the SIMPER procedure (Clarke 1993, Clarke \& Warwick 1994).

Multivariate ordination (CANOCO version 4.5, ter Braak \& Šmilauer 2002) was used to identify correlations between benthic commu- nities and sediment grain sizes. The relationship between species and sediment grain size classes was calculated using canonical correlation analysis (CCA) with Monte Carlo permutation (9999 permutations) and the forward-selection option (ter Braak 1989). A significance threshold of $\alpha=0.05$ was adopted for all statistical tests.

\section{RESULTS}

\section{Sediment characterization}

Sediment organic content was low, varying between 1 and $3 \%$, and did not differ significantly between treatments or sites within treatments (Table 1); Site R1 had higher (mean \pm SE: $2.44 \pm 0.06 \%$ ) and Site R3 lower $(1.82 \pm 0.08 \%)$ sediment organic content.

Table 1. Results of 4 factor partly-nested analyses of variance (ANOVAs) testing the effect of Treatment (T) and Site (S) nested within Treatment, Orientation (O), and Distance (D) and their interactions on sediment organic content, mean grain size, sorting, and skewness. Significant values $(p<0.05)$ in bold

\begin{tabular}{|c|c|c|c|c|c|c|}
\hline \multirow{2}{*}{$\begin{array}{l}\text { Sources of } \\
\text { variation }\end{array}$} & \multicolumn{3}{|c|}{ Organic content } & \multicolumn{3}{|c|}{ Mean grain size ${ }^{a}$} \\
\hline & $\mathrm{df}$ & $\mathrm{MS}$ & $F$ & $\mathrm{df}$ & MS & $F$ \\
\hline $\mathrm{T}$ & 1 & 0.258 & 0.074 & 1 & 1.720 & 5.728 \\
\hline $\mathrm{S}(\mathrm{T})$ & 2 & 3.462 & 13.307 & 4 & 0.300 & 14.394 \\
\hline $\mathrm{O}$ & 1 & 0.171 & 0.768 & 1 & 0.014 & 1.832 \\
\hline $\mathrm{D}$ & 3 & 0.117 & 0.825 & 3 & 0.096 & 6.090 \\
\hline $\mathrm{T} \times \mathrm{O}$ & 1 & 0.089 & 0.399 & 1 & 0.003 & 0.368 \\
\hline $\mathrm{T} \times \mathrm{D}$ & 3 & 0.181 & 1.279 & 3 & 0.104 & 6.617 \\
\hline $\mathrm{O} \times \mathrm{D}$ & 3 & 0.314 & 3.023 & 3 & 0.003 & 1.398 \\
\hline $\mathrm{T} \times \mathrm{O} \times \mathrm{D}$ & 3 & 0.411 & 3.960 & 3 & 0.003 & 1.110 \\
\hline $\mathrm{S}(\mathrm{T}) \times \mathrm{O}$ & 2 & 0.222 & 2.142 & 4 & 0.008 & 3.153 \\
\hline $\mathrm{S}(\mathrm{T}) \times \mathrm{D}$ & 6 & 0.142 & 1.364 & 12 & 0.016 & 6.547 \\
\hline $\mathrm{S}(\mathrm{T}) \times \mathrm{O} \times \mathrm{D}$ & 6 & 0.104 & 0.610 & 12 & 0.002 & 0.379 \\
\hline \multirow[t]{3}{*}{ Residual } & 96 & 0.401 & & 144 & 0.006 & \\
\hline & \multicolumn{3}{|c|}{ Sorting $^{\mathrm{a}}$} & \multicolumn{3}{|c|}{ Skewness } \\
\hline & $\mathrm{df}$ & MS & $F$ & $\mathrm{df}$ & MS & $F$ \\
\hline $\mathrm{T}$ & 1 & 0.102 & 1.255 & 1 & 2.632 & 0.702 \\
\hline $\mathrm{S}(\mathrm{T})$ & 4 & 0.081 & 53.956 & 4 & 3.749 & 29.853 \\
\hline $\mathrm{O}$ & 1 & 0.001 & 1.882 & 1 & 0.350 & 5.483 \\
\hline $\mathrm{D}$ & 3 & $3.0 \times 10^{-5}$ & 0.011 & 3 & 0.911 & 7.030 \\
\hline $\mathrm{T} \times \mathrm{O}$ & 1 & $6.7 \times 10^{-8}$ & $2.0 \times 10^{-4}$ & 1 & 0.117 & 1.835 \\
\hline $\mathrm{T} \times \mathrm{D}$ & 3 & 0.001 & 0.511 & 3 & 0.809 & 6.240 \\
\hline $\mathrm{O} \times \mathrm{D}$ & 3 & 0.003 & 1.729 & 3 & 0.045 & 0.662 \\
\hline $\mathrm{T} \times \mathrm{O} \times \mathrm{D}$ & 3 & 0.001 & 0.767 & 3 & 0.035 & 0.519 \\
\hline $\mathrm{S}(\mathrm{T}) \times \mathrm{O}$ & 4 & $3.9 \times 10^{-4}$ & 0.234 & 4 & 0.064 & 0.940 \\
\hline $\mathrm{S}(\mathrm{T}) \times \mathrm{D}$ & 12 & 0.003 & 1.666 & 12 & 0.130 & 1.910 \\
\hline $\mathrm{S}(\mathrm{T}) \times \mathrm{O} \times \mathrm{D}$ & 12 & 0.002 & 2.637 & 12 & 0.068 & 1.140 \\
\hline Residual & 144 & 0.001 & & 144 & 0.060 & \\
\hline
\end{tabular}


All Chausey Archipelago samples were characterized by coarse sediment with a high content of bioclastic material (i.e. sediment composed of fragments of organic skeletal materials). Reference sites were characterized by coarser sediments than mussel sites (Fig. 3a,b); both mussel and reference sites contained less than $1 \%$ fine sediments $(<125 \mu \mathrm{m}$, i.e. mud and very fine sand).
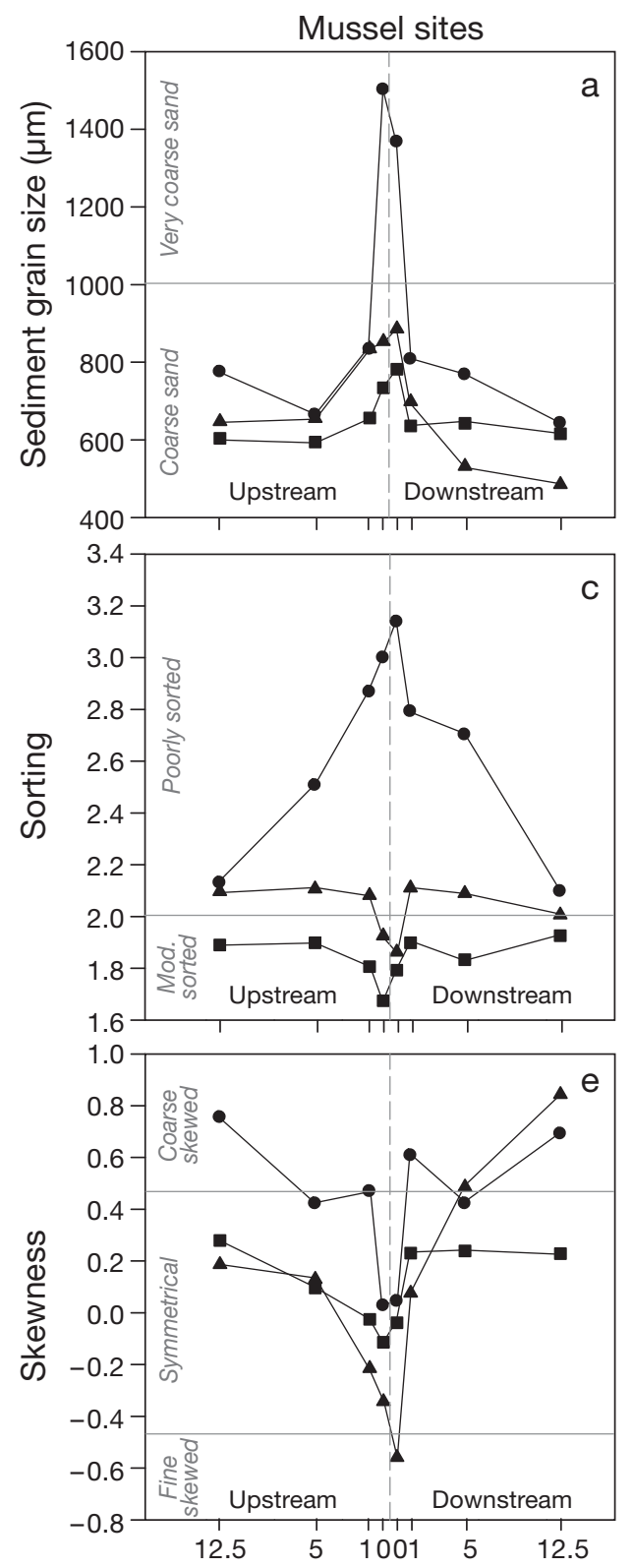

Small-scale patterns of sediment size sorting differed between mussel and reference sites as indicated by the significant interaction between treatment and distance (Table 1). In short, there was no structure apparent in reference locations, but sediments at mussel sites showed spatial structure such that sediments were coarser close to bouchots (distance $=0 \mathrm{~m}$ ) than further from them. This trend was
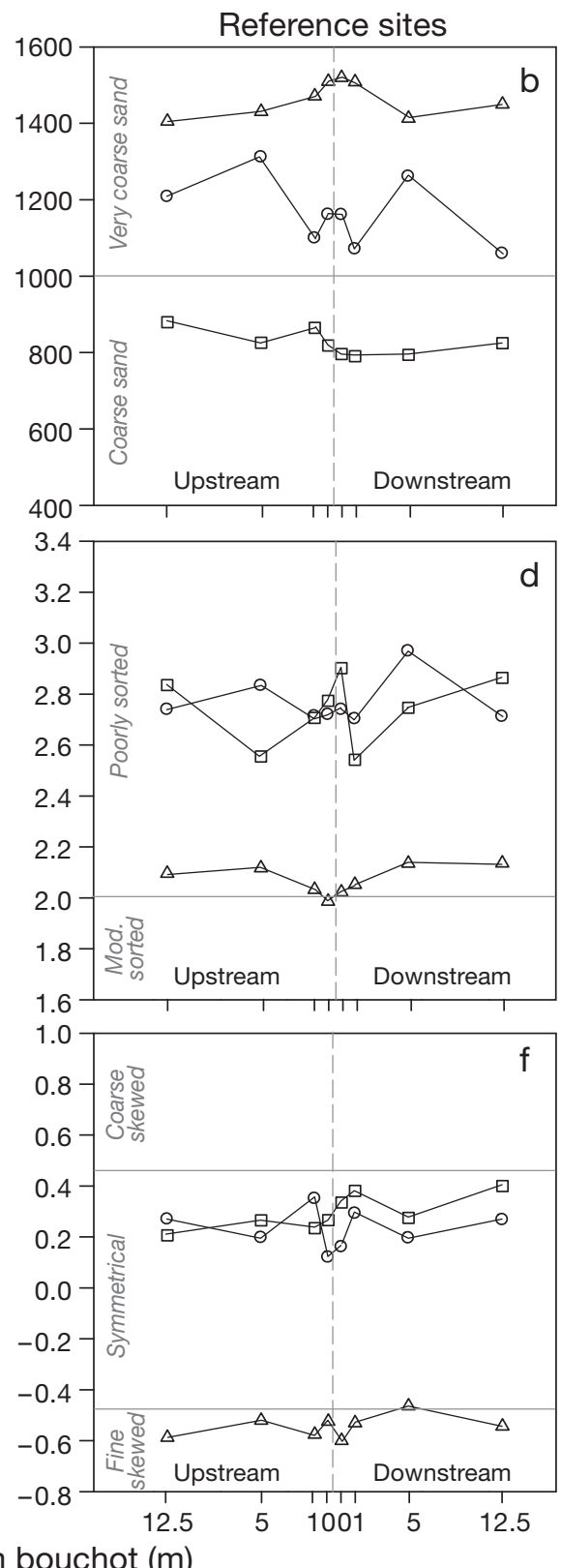

Fig. 3. $(\mathrm{a}, \mathrm{b})$ Mean sediment grain size $(\mu \mathrm{m}),(\mathrm{c}, \mathrm{d})$ sorting and $(\mathrm{e}, \mathrm{f})$ skewness $(\mathrm{n}=4)$ at 4 distances $(0,1,5$ and $12.5 \mathrm{~m})$ from the

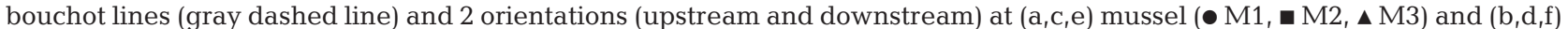
reference (o R1, $\square$ R2, $\Delta$ R3) sites. Classifications of mean grain size (coarse sand, very coarse sand), sorting (poorly sorted, moderately sorted) and skewness (coarse skewed, symmetrical, fine skewed) were made according to Blott \& Pye (2001). SEs were not included to avoid overlap in the graph but had the following ranges: mean grain size 10.83 to $251.85 \mu \mathrm{m}$; sorting 0.02 to 0.17 ; and skewness 0.04 to 0.18 
particularly clear for Site M1 (Fig. 3a). Similarly, skewness also showed small-scale effects due to mussel farm structures as sediments close to bouchots were skewed to more fine sediments than those further away. This trend was not apparent at reference sites (Fig. 3e,f). Analysis of sediments showed significant variation among sites within treatments in terms of mean grain size, sorting, and skewness (Table 1). For all univariate sediment parameters, Sites R1 and R2 were most similar, although R2 was characterized by slightly finer sediments (Fig. 3b). Both of these sites were poorly sorted and symmetrical, whereas site R3 was finely skewed (Fig. 3d,f). Sites M2 and M3 were composed of finer sediment than the M1 mussel site; both were moderately to poorly sorted, and M1 showed an inverse sorting trend (Fig. 3c). Skewness was almost symmetrical for the 3 mussel sites (Fig. 3e).

\section{Benthic community characterization}

A total of 201 taxa were identified in this study, including 2 new species of polychaetes in the family Syllidae (Olivier et al. in press). Polychaetes and bivalves were the 2 dominant groups at both mussel and reference sites. These taxonomic groups were dominated by 21 species of syllids (accounting for
$73 \%$ of the total abundance of all polychaetes) and the bivalve Goodallia triangularis (98\% of the total abundance of all bivalves), respectively. For polychaetes, the syllid Salvatoria swedmarki was clearly associated with reference sites, whereas Sphaerosyllis bulbosa (Syllidae) was more abundant close to the bouchots (Fig. 4a,b). G. triangularis was observed almost exclusively at mussel sites and was significantly more abundant closest to the bouchots than at other distances from them (Table 2). Similarly, the density of $S$. bulbosa was significantly greater near the mussel structures than at other distances from them (Table 2), and this species was also more abundant at mussel sites (Fig. 4b).

Abundance $(\mathrm{N})$ and variation in taxonomic distinctness $\left(\Lambda^{+}\right)$varied as a function of the interaction between treatment and distance (Table 3 ) such that each variable did not differ among distances at reference sites but did so at mussel sites. At mussel sites, both these metrics were greater at the $0 \mathrm{~m}$ distance but there were fewer taxa close to the mussel structures relative to other distances (Fig. 5a,f). Moreover, all univariate community characteristics differed significantly among sites studied within treatments (Table 3), although replicate reference sites did not differ except with respect to the number of taxa (lower at R3), evenness and average taxonomic distinctness (both higher at R3). Mussel sites were char-
Fig. 4. Salvatoria swedmarki, Sphaerosyllis bulbosa, Syllis garciai and Goodallia triangularis. Abundance (ind. $\mathrm{m}^{-2}$, mean $+\mathrm{SE}$, $\mathrm{n}=24$ observations distance ${ }^{-1}$ ) of 4 species consistently collected at mussel (M1, M2, M3 combined) and reference sites (R1, R2, R3 combined) at 0 (white), 1 (gray), 5 (dark gray), and $12.5 \mathrm{~m}$ (black) from the mussel aquaculture structures: (a) S. swedmarki, (b) $S$. bulbosa, (c) S. garciai, and (d) G. triangularis. Different letters indicate significant differences for the interaction between treatment and distance (see Table 2 for test results)
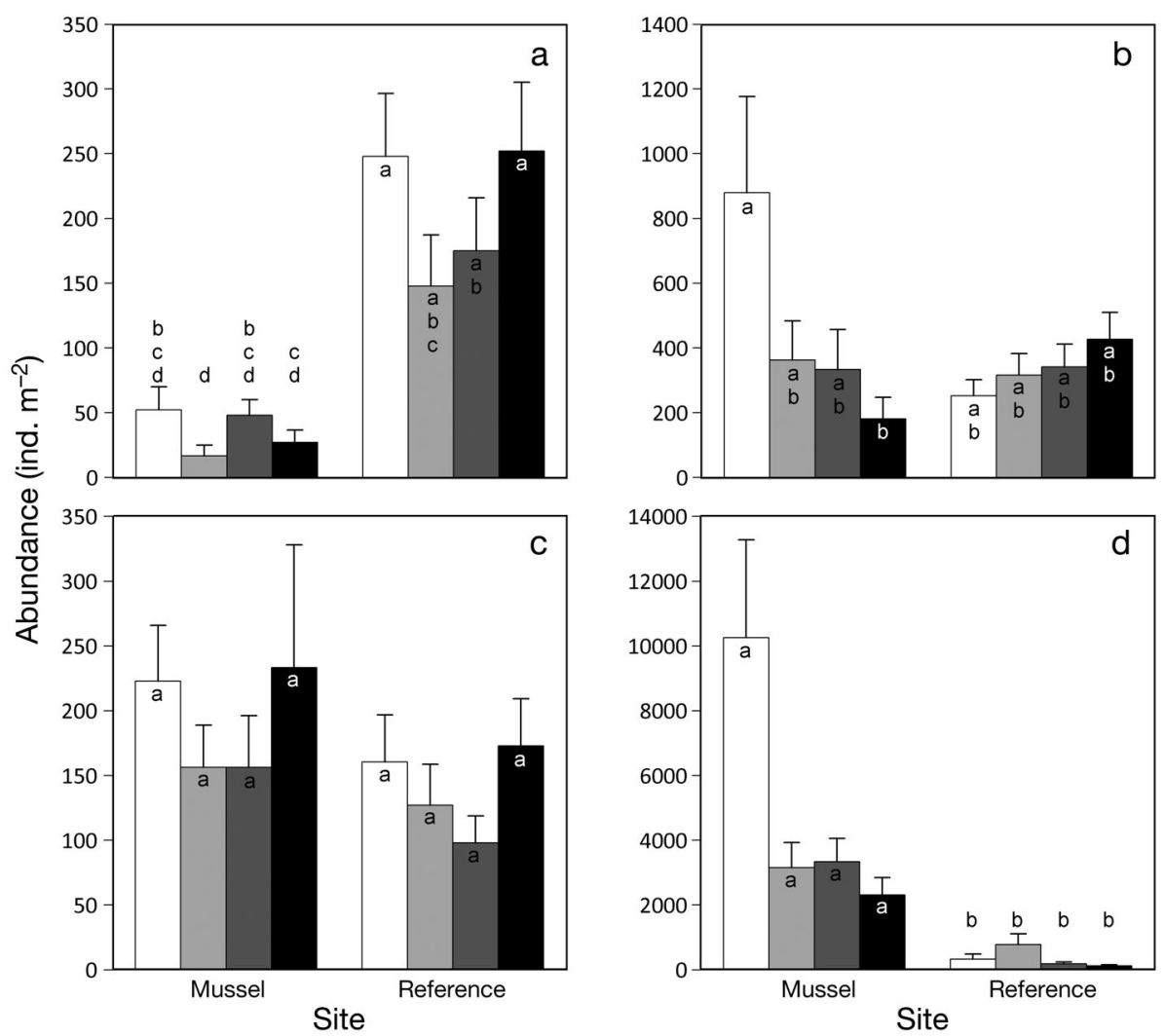
Table 2. Results of 4-way partly-nested analyses of variance (ANOVAs) testing the effect of Treatment (T) and Site (S) nested within Treatment, Orientation (O), and Distance (D) and their interactions on the abundances of the polychaetes Salvatoria swedmarki, Sphaerosyllis bulbosa, Syllis garciai and the bivalve Goodallia triangularis. All data were $\log _{10}(x+1)$ transformed prior to analysis. Significant values in bold. When convenient, pooling procedures were applied according to Underwood (1997). nd: not determined

\begin{tabular}{|c|c|c|c|c|c|c|}
\hline \multirow{2}{*}{$\begin{array}{l}\text { Sources of } \\
\text { variation }\end{array}$} & \multicolumn{3}{|c|}{ Salvatoria swedmarki } & \multicolumn{3}{|c|}{ Sphaerosyllis bulbosa } \\
\hline & df & MS & $F$ & & Af $\quad$ MS & $F$ \\
\hline $\mathrm{T}$ & 1 & 6.188 & 1.900 & & 0.146 & 0.021 \\
\hline $\mathrm{S}(\mathrm{T})$ & 4 & 3.257 & 28.012 & & 7.001 & $\quad 36.499$ \\
\hline $\mathrm{O}$ & 1 & 0.021 & 0.252 & & $3.0 \times 10$ & $0^{-4} \quad 0.002$ \\
\hline $\mathrm{D}$ & 3 & 0.211 & 2.611 & & 0.134 & 1.063 \\
\hline $\mathrm{T} \times \mathrm{O}$ & 1 & $2.5 \times 10^{-}$ & $-61.0 \times 10^{-4}$ & & 0.006 & 0.040 \\
\hline $\mathrm{T} \times \mathrm{D}$ & 3 & 0.105 & 1.298 & & 0.594 & 4.699 \\
\hline $\mathrm{O} \times \mathrm{D}$ & 3 & 0.046 & 0.984 & & 0.055 & 0.761 \\
\hline $\mathrm{T} \times \mathrm{O} \times \mathrm{D}$ & 3 & 0.003 & 0.068 & & 0.022 & 0.300 \\
\hline $\mathrm{S}(\mathrm{T}) \times \mathrm{O}$ & 4 & 0.082 & 1.762 & & 0.139 & 1.899 \\
\hline $\mathrm{S}(\mathrm{T}) \times \mathrm{D}$ & 12 & 0.081 & 1.741 & & 0.126 & 1.736 \\
\hline $\mathrm{S}(\mathrm{T}) \times \mathrm{O} \times \mathrm{D}$ & 12 & 0.047 & 0.939 & 1 & 0.073 & 0.627 \\
\hline Residual & 144 & 0.050 & & 14 & 0.116 & \\
\hline \multirow{2}{*}{$\begin{array}{l}\text { Sources of } \\
\text { variation }\end{array}$} & \multicolumn{3}{|c|}{ Syllis garciai } & \multicolumn{3}{|c|}{ Goodallia triangularis } \\
\hline & df & MS & $F$ & $\mathrm{df}$ & MS & $F$ \\
\hline $\mathrm{T}$ & 1 & 0.456 & 0.177 & 1 & 47.460 & 5.830 \\
\hline $\mathrm{S}(\mathrm{T})$ & 4 & 2.583 & 13.024 & 4 & 8.141 & 30.417 \\
\hline $\mathrm{O}$ & 1 & 0.020 & 0.109 & 1 & $1.0 \times 10^{-5}$ & $1.0 \times 10^{-4}$ \\
\hline $\mathrm{D}$ & 3 & 0.131 & 1.348 & 3 & 0.567 & 1.703 \\
\hline $\mathrm{T} \times \mathrm{O}$ & 1 & 0.431 & 2.359 & 1 & 0.009 & 0.084 \\
\hline $\mathrm{T} \times \mathrm{D}$ & 3 & 0.012 & 0.118 & 3 & 0.387 & 1.163 \\
\hline $\mathrm{O} \times \mathrm{D}$ & 3 & 0.087 & 1.050 & 3 & $0.448^{\mathrm{a}}$ & 2.593 \\
\hline $\mathrm{T} \times \mathrm{O} \times \mathrm{D}$ & 3 & 0.263 & 3.216 & 3 & $0.028^{\mathrm{a}}$ & 0.164 \\
\hline $\mathrm{S}(\mathrm{T}) \times \mathrm{O}$ & 4 & 0.183 & 2.234 & 4 & 0.108 & 0.622 \\
\hline $\mathrm{S}(\mathrm{T}) \times \mathrm{D}$ & 12 & 0.098 & 1.193 & 12 & 0.333 & 1.927 \\
\hline $\mathrm{S}(\mathrm{T}) \times \mathrm{O} \times \mathrm{D}$ & 12 & 0.082 & 1.138 & nd & nd & nd \\
\hline Residual & 144 & 0.072 & & 156 & 0.173 & \\
\hline
\end{tabular}

acterized by a moderate abundance of organisms, a lower diversity, and a greater number of taxa than reference sites (Fig. 5a,b,d). The infaunal sediment community from the Chausey Archipelago was classified as slightly disturbed based on AMBI coefficients (Fig. 6), and these did not differ significantly among distances $\left(F_{3,12}=1.89, \mathrm{p}=0.18\right)$. Most identified taxa were classified into ecological group II and are considered to be indifferent to pollution.

Benthic community structure varied as a function of the interaction between treatment and distance such that communities differed between mussel and reference sites and among distances at mussel sites but not among distances at reference sites (Table 4). As illustrated by a non-metric multidimensional scaling (nMDS) plot (Fig. 7), within mussel sites communities at $0 \mathrm{~m}$ differed from those at 5 and $12.5 \mathrm{~m}$
(Table 5). SIMPER analysis showed that differences between communities at $0 \mathrm{~m}$ and those at other distances were mostly related to a greater abundance of 3 species: the bivalve Goodallia triangularis and the polychaetes Sphaerosyllis bulbosa and S. taylori, all of which were more abundant close to mussel structures (Table 6). SIMPER analysis also showed that the polychaete Cirriformia tentaculata was more abundant further from bouchots and contributed to the dissimilarity among distances. Analysis of community structure based on presence/absence-transformed data showed that sites within treatments differed but that no other effect or interaction was significant (Table 4).

\section{Sediment grain size and benthic community relationships}

Gradient lengths were first explored using CCA to estimate standard deviations. Detrended canonical analysis (DCA), detrending by segments, provides values between 2.6 to 3.7 SD which, according to Lepš \& Šmilauer (2003), indicate that both linear and unimodal methods may be used. Consequently, unimodal ordination was used for subsequent analyses. CCA showed a significant relationship between benthic community structure and 14 sediment grain sizes. Together, the first and second principal CCA axes accounted for $45.0 \%$ of the relationship between community structure and sediment grain size $(27.1$ and $17.9 \%$, respectively). Sediments of 2360 to $5600 \mu \mathrm{m}$ (very fine to fine gravel) were important factors describing the first axis (correlation of 0.63 to 0.77 , respectively). On the second axis, 2000 to $2800 \mu \mathrm{m}$ sediments (very coarse sand to very fine gravel) were the most positively correlated factors ( 0.30 to 0.42 , respectively).

The spatial arrangement of samples relative to sediment grain sizes showed 3 distinct patterns (Fig. 8). Samples in the upper-right section of the ordination graph were strongly correlated to coarse sediments (gravel); these were collected from the reference sites (R1, R2, R3). Samples grouped in the left portion of the graph were collected at the M1 and M2 sites and were associated with finer sediments (sand). The third group is in the lower right portion of the figure and is composed of samples from Site M1. These samples were best correlated to both coarse (fine 
Table 3. Results of 4 factor partly-nested analyses of variance (ANOVAs) testing the effect of Treatment (T), Site (S) nested within Treatment, Orientation (O), Distance (D) and their interactions on the univariate ecological indicators. Significant values $(p<0.05)$ in bold. When convenient, pooling procedures were applied according to Underwood (1997). nd: not determined

\begin{tabular}{|c|c|c|c|c|c|c|c|c|c|}
\hline \multirow{2}{*}{$\begin{array}{l}\text { Sources of } \\
\text { variation }\end{array}$} & \multicolumn{3}{|c|}{ Abundance (ind. m²) } & \multicolumn{3}{|c|}{ No. of $\operatorname{tax} a^{b}$} & \multicolumn{3}{|c|}{ Evenness index } \\
\hline & $\mathrm{df}$ & MS & F & df & & $F$ & $\mathrm{df}$ & MS & $F$ \\
\hline $\mathrm{T}$ & 1 & 7.130 & 0.013 & 1 & & 2.121 & 1 & 2.875 & 3.644 \\
\hline $\mathrm{S}(\mathrm{T})$ & 4 & 564.198 & 13.561 & 4 & & 27.801 & 4 & 0.789 & 15.095 \\
\hline $\mathrm{O}$ & 1 & 15.755 & 0.379 & 1 & & 0.273 & 1 & 0.009 & 0.212 \\
\hline $\mathrm{D}$ & 3 & $59.352^{\mathrm{a}}$ & 3.646 & 3 & & 3.022 & 3 & 0.010 & 0.446 \\
\hline $\mathrm{T} \times \mathrm{O}$ & 1 & 20.672 & 0.497 & 1 & & 1.187 & 1 & 0.021 & 0.470 \\
\hline $\mathrm{T} \times \mathrm{D}$ & 3 & $44.464^{\mathrm{a}}$ & 2.731 & 3 & & 3.392 & 3 & 0.014 & 0.643 \\
\hline $\mathrm{O} \times \mathrm{D}$ & 3 & $6.477^{\mathrm{a}}$ & 0.398 & 3 & & 0.992 & 3 & 0.022 & 1.473 \\
\hline $\mathrm{T} \times \mathrm{O} \times \mathrm{D}$ & 3 & $17.505^{\mathrm{a}}$ & 1.075 & 3 & & 0.552 & 3 & 0.002 & 0.135 \\
\hline $\mathrm{S}(\mathrm{T}) \times \mathrm{O}$ & 4 & 41.604 & 2.556 & 4 & & 0.711 & 4 & 0.044 & 3.044 \\
\hline $\mathrm{S}(\mathrm{T}) \times \mathrm{D}$ & nd & nd & nd & 12 & & 1.640 & 12 & 0.022 & 1.538 \\
\hline $\mathrm{S}(\mathrm{T}) \times \mathrm{O} \times \mathrm{D}$ & nd & nd & nd & 12 & & 1.134 & 12 & 0.015 & 1.530 \\
\hline \multirow[t]{3}{*}{ Residual } & 168 & 16.280 & & 144 & & & 144 & 0.010 & \\
\hline & \multicolumn{3}{|c|}{ Diversity index } & \multicolumn{3}{|c|}{ Average taxonomic distinctness } & \multicolumn{3}{|c|}{ Variation in taxonomic distinctness } \\
\hline & $\mathrm{df}$ & MS & $F$ & $\mathrm{df}$ & MS & $F$ & df & MS & $F$ \\
\hline $\mathrm{T}$ & 1 & 17.535 & 2.275 & 1 & 0.17 & $2.0 \times 10^{-4}$ & 1 & 118 & $1.0 \times 10^{-4}$ \\
\hline $\mathrm{S}(\mathrm{T})$ & 4 & 7.707 & 9.725 & 4 & 1133.81 & 41.548 & 4 & 2187504 & 18.329 \\
\hline $\mathrm{O}$ & 1 & $2.0 \times 10^{-4}$ & $3.0 \times 10^{-4}$ & 1 & 1.32 & 0.059 & 1 & 67294 & 0.462 \\
\hline $\mathrm{D}$ & 3 & 0.018 & 0.072 & 3 & 56.51 & 1.303 & 3 & 364723 & 5.014 \\
\hline $\mathrm{T} \times \mathrm{O}$ & 1 & 0.012 & 0.019 & 1 & 3.17 & 0.142 & 1 & 121871 & 0.837 \\
\hline $\mathrm{T} \times \mathrm{D}$ & 3 & 0.039 & 0.154 & 3 & 30.84 & 0.711 & 3 & 284785 & 3.915 \\
\hline $\mathrm{O} \times \mathrm{D}$ & 3 & 0.245 & 2.486 & 3 & 25.64 & 0.667 & 3 & 46425 & 0.469 \\
\hline $\mathrm{T} \times \mathrm{O} \times \mathrm{D}$ & 3 & 0.064 & 0.648 & 3 & 26.47 & 0.688 & 3 & 123173 & 1.245 \\
\hline $\mathrm{S}(\mathrm{T}) \times \mathrm{O}$ & 4 & 0.642 & 6.514 & 4 & 22.38 & 0.582 & 4 & 145571 & 1.471 \\
\hline $\mathrm{S}(\mathrm{T}) \times \mathrm{D}$ & 12 & 0.250 & 2.532 & 12 & 43.37 & 1.128 & 12 & 72749 & 0.735 \\
\hline $\mathrm{S}(\mathrm{T}) \times \mathrm{O} \times \mathrm{D}$ & 12 & 0.099 & 0.837 & 12 & 38.46 & 1.450 & 12 & 98972 & 1.135 \\
\hline Residual & 144 & 0.118 & & 144 & 26.53 & & 144 & 87208 & \\
\hline
\end{tabular}

gravel) and fine sediments (silt). The species Sphaerosyllis bulbosa was strongly associated with very fine sediments (silt), whereas Goodallia triangularis and the syllids Salvatoria swedmarki, Sphaerosyllis taylori, and Syllis garciai were correlated with coarse sand.

\section{DISCUSSION}

This study provides an important baseline in understanding the effects of bouchot mussel aquaculture on macrobenthic communities of coarse sediments in a high energy intertidal system, a relatively unknown habitat in comparison to subtidal muddy ones. Whereas the effects of shellfish farming on lowenergy soft-bottom benthic environments are fairly well known (see review in McKindsey et al. 2011), the influence of mussel culture in high energy intertidal systems remains undocumented. In this context, the present study focusing on the Glycymeris glycymeris coarse sediment habitat of the Chausey
Archipelago is of primary importance. Results support our initial hypothesis that mussel aquaculture structures (bouchots) have clear meso- and smallscale effects on both sediment properties and benthic community structure.

Organic enrichment of sediments in the mussel leases was not detected, even close to the bouchots. This contrasts with the majority of studies done in suspended farm systems where cultured bivalves biodeposition leads to organic loading. In the present study, the observed modifications of the coarse sediment benthic communities are likely primarily affected by changes in the hydrosedimentary patterns due to the presence of rugosity elements in the benthic boundary layer. Hartstein \& Rowden (2004) found that the only (of 3) mussel culture site studied that was not organically enriched was influenced by the strongest hydrodynamic regime. High-energy systems with strong currents limit organic enrichment by enhancing the dispersal of mussel biodeposits. Although the present study did not detect sedimen- 

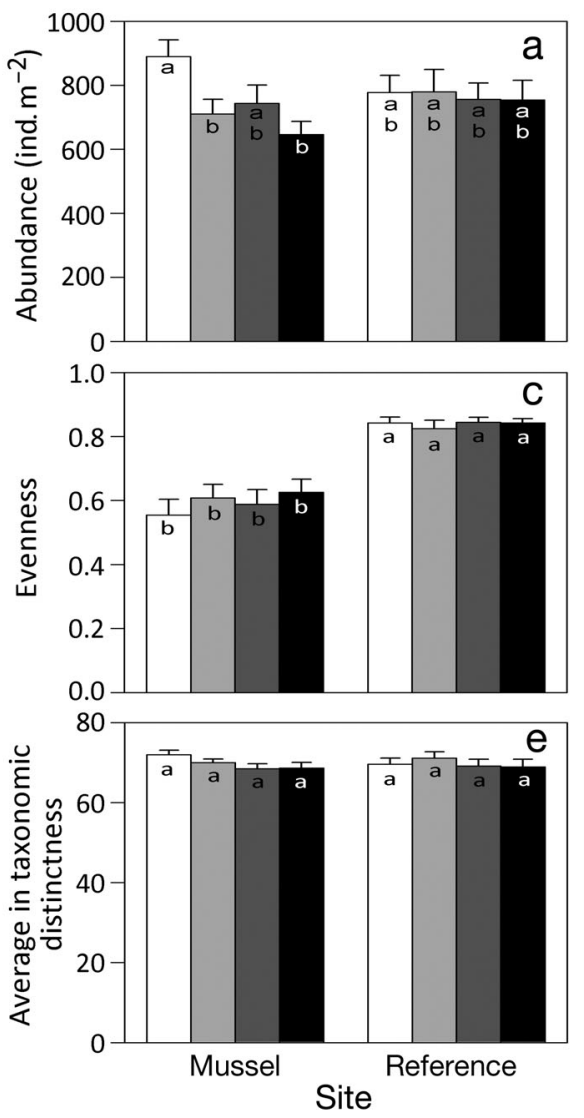
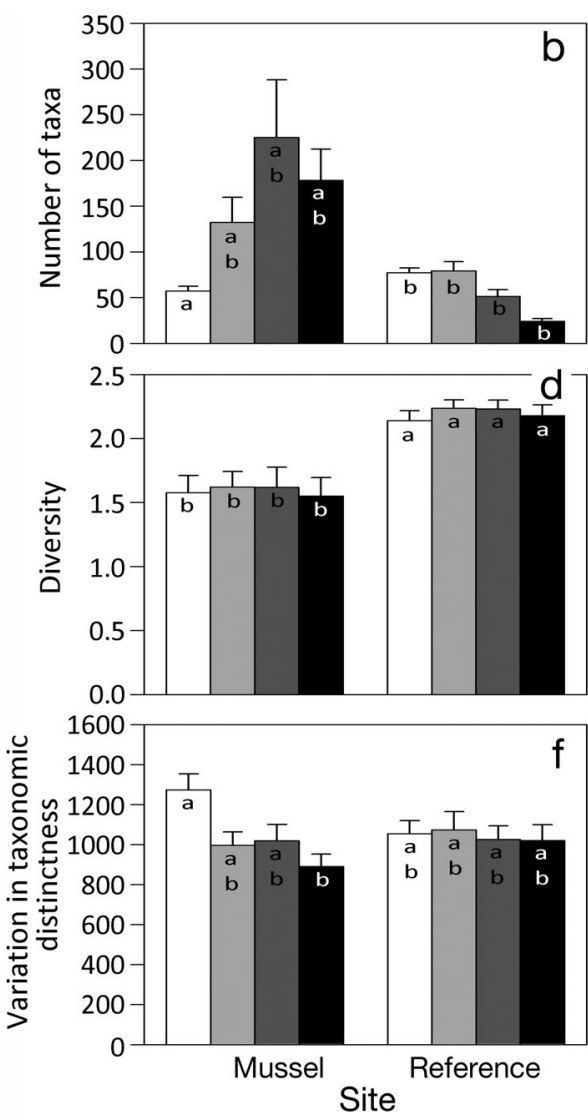

Fig. 5. Macrofauna characteristics (mean $+\mathrm{SE}, \mathrm{n}=24$ observations distance $^{-1}$ ) at mussel (M1, M2, M3 combined) and reference sites (R1, R2, R3 combined) at 0 (white), 1 (gray), 5 (dark gray), and $12.5 \mathrm{~m}$ (black) from bouchot lines. (a) Abundance of individuals (ind. $\mathrm{m}^{-2}$ ), (b) number of taxa, (c) Pielou's evenness, (d) ShannonWiener diversity, (e) average in taxonomic distinctness, and (f) variation in taxonomic distinctness. Different letters indicate significant differences for the interaction between treatment and distance (see Table 3 for test results) tary enrichment, sampling was done at low tide and not during the period of slack neap tide when tidal currents could allow for temporary local accumulation of biodeposits. As the more labile portion of biodeposits is released within hours of deposition (Fabiano et al. 1994), the influence of organic loading may occur over short time scales, when the tide is high and infauna is most active.

A complementary study done in the Chausey Archipelago at the same time of the year and under the same tidal regime showed that mussel farming affects the total lipid content and fatty acids profiles in sub-surface sediments (Suroy 2009). Particulate organic matter in sediments was shown to originate mainly from diatoms and brown algae at both mussel and reference sites. However, sediment fatty acid profiles differed significantly between mussel and reference sites in the spring, indicating a change in the nature of the organic matter present. This may be due to the rapid release of the more labile portion of biodeposits (Fabiano et al. 1994, Carlsson et al. 2010). Although these 2 Chausey studies provide different results with respect to organic matter enrichment, the results are not entirely inconsistent. Rather, they

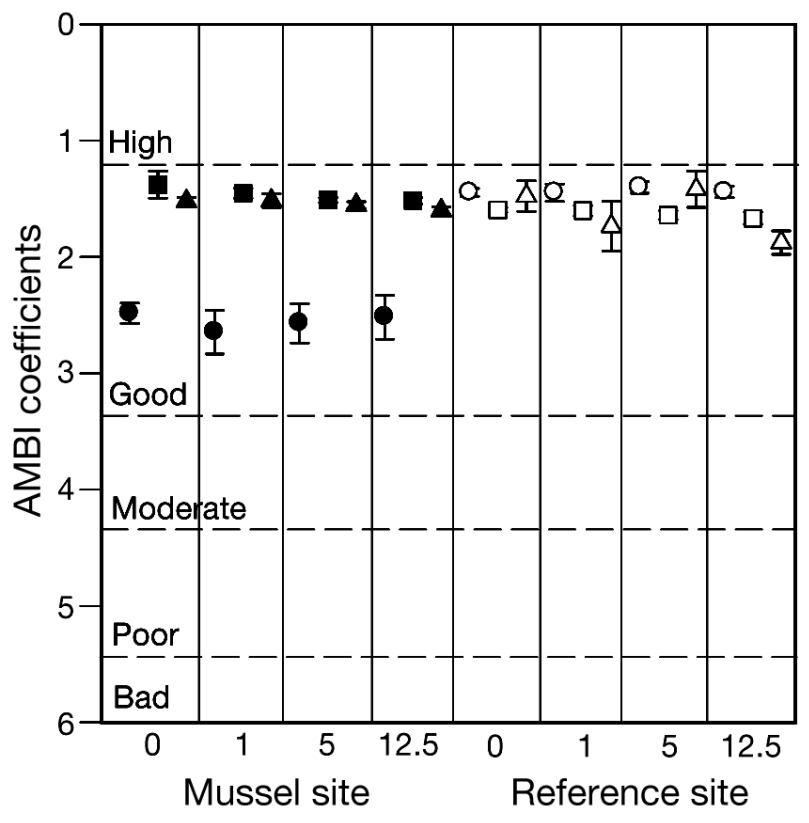

Fig. 6. AZTI marine biotic index (AMBI coefficients, mean \pm $\mathrm{SE}, \mathrm{n}=24$ observations distance $\left.{ }^{-1}\right)$ at mussel, $(\bullet$ M1, M2, $\Delta$ M3) and reference (O R1, $\square$ R2, $\Delta$ R3) sites. Horizontal dashed lines separate EcoQ classes as defined by Borja et al. (2000), whereas vertical solid lines mark the distances from the bouchot lines $(0,1,5$ and $12.5 \mathrm{~m})$ 
Table 4. Results of permutational multivariate analyses of variance (PERMANOVAs) testing the effect of Treatment (T), Site (S) nested within Treatment, Orientation (O), Distance (D) and their interactions on the benthic assemblage based on the Bray-Curtis dissimilarity matrix. The species assemblage was calculated on untransformed data and on presence/absence transformed data. Significant values $(p<0.05)$ in bold

\begin{tabular}{|c|c|c|c|c|c|c|c|}
\hline \multirow{2}{*}{$\begin{array}{l}\text { Sources of } \\
\text { variation }\end{array}$} & \multirow[t]{2}{*}{ df } & \multicolumn{3}{|c|}{ Untransformed data } & \multicolumn{3}{|c|}{ Presence/absence } \\
\hline & & MS & Pseudo- $F$ & $\mathrm{p}($ perm $)$ & MS & Pseudo- $F$ & $\mathrm{p}($ perm $)$ \\
\hline $\mathrm{T}$ & 1 & 85398 & 1.806 & 0.1155 & 36293 & 1.330 & 0.2453 \\
\hline $\mathrm{S}(\mathrm{T})$ & 4 & 47297 & 30.871 & 0.0001 & 27289 & 20.404 & 0.0001 \\
\hline $\mathrm{O}$ & 1 & 1313 & 0.719 & 0.6139 & 2416 & 1.873 & 0.1521 \\
\hline D & 3 & 3201 & 1.672 & 0.0342 & 2425 & 1.482 & 0.0590 \\
\hline $\mathrm{T} \times \mathrm{O}$ & 1 & 2577 & 1.410 & 0.2807 & 2873 & 2.228 & 0.1068 \\
\hline $\mathrm{T} \times \mathrm{D}$ & 3 & 3394 & 1.773 & 0.0176 & 2157 & 1.319 & 0.1393 \\
\hline $\mathrm{O} \times \mathrm{D}$ & 3 & 1625 & 1.014 & 0.4511 & 1209 & 0.895 & 0.6036 \\
\hline $\mathrm{T} \times \mathrm{O} \times \mathrm{D}$ & 3 & 1322 & 0.825 & 0.7293 & 721 & 0.534 & 0.9452 \\
\hline $\mathrm{S}(\mathrm{T}) \times \mathrm{O}$ & 4 & 1828 & 1.193 & 0.1344 & 1290 & 0.964 & 0.5550 \\
\hline $\mathrm{S}(\mathrm{T}) \times \mathrm{D}$ & 12 & 1915 & 1.250 & 0.0160 & 1636 & 1.223 & 0.0416 \\
\hline $\mathrm{S}(\mathrm{T}) \times \mathrm{O} \times \mathrm{D}$ & 12 & 1602 & 1.046 & 0.3280 & 1350 & 1.010 & 0.4597 \\
\hline Residual & 144 & 1532 & & & 1337 & & \\
\hline
\end{tabular}

1979). At the meso-scale $(\mathrm{km})$, sediments were finer at mussel farms than at reference sites, likely reflecting either decreased hydrodynamics or a stabilization of the seabed due to the presence of large numbers of bouchots. For example, currents at culture sites may be reduced by increased drag due to bouchots at culture sites or from dampened wave energy within sites (Ottman \& Sornin 1985, Vaucourt \& Bonnot-Courtois 1992). At a more local scale $(\mathrm{m})$, scouring occurs near the poles and leads to a coarsening of impacted sediments (Sornin 1981, SEAMER 2000). The presence of structures placed in a marine environment, such as bouchots, modifies localized flow patterns (SEAMER 2000), increasing both flow speed and

demonstrate the need for sensitive analyses to detect the effects of mussel aquaculture in highly dynamic systems which may be particularly necessary in coarse and permeable sediments.

In contrast to the lack of organic enrichment in the mussel farms, there was a progressive coarsening and decrease in skewness of sediments in the direction of bouchots. This suggests the importance of local hydrodynamic regimes on sediment properties in this part of the English Channel, which is mainly dominated by coarse sediment habitats (Retière

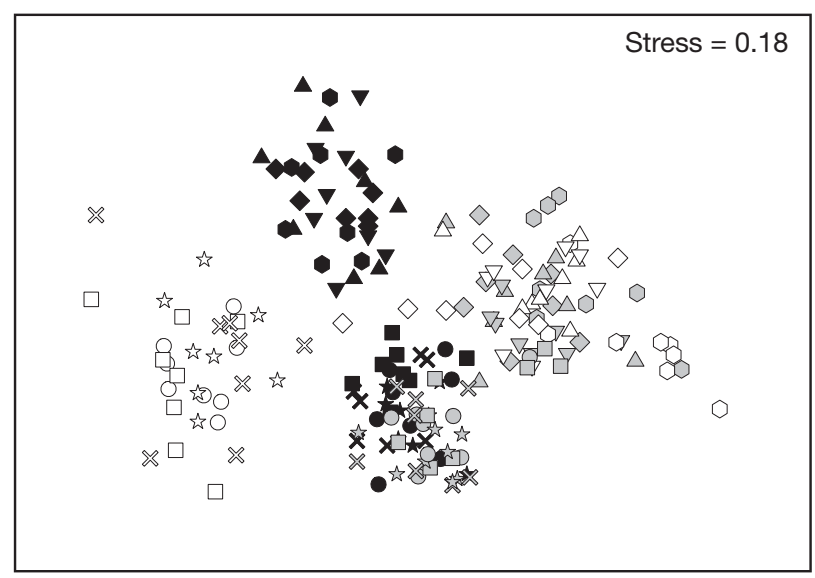

Fig. 7. Non-metric multidimensional scaling (nMDS) ordination based on Bray-Curtis dissimilarity matrix calculated on untransformed data for benthic samples collected at mussel farm and reference sites at 4 distances from the bouchot lines $(\bullet 0, \Delta 1, \nabla 5,-12.5 \mathrm{~m})$ and the centre of reference areas $(\bullet 0,1,5, \star 12.5 \mathrm{~m})$. Reference and mussel farm sites 1,2 , and 3 are indicated by black, grey, and white fills, respectively (see Table 5 for test results) turbulence intensity (Whitehouse 1998). Numerous phenomena result from these changes including flow reduction, wave reflection and diffraction, and the creation of pressure differentials in sediments and bed liquefaction, potentially allowing material to be transported away by currents (Sumer et al. 2001). These phenomena usually increase local sediment transport capacity and thus scour (Whitehouse 1998). In the Chausey Archipelago, this was visually observed in the field at a local scale around individual bouchots and at the farm scale, resulting in both depressions in sediments upstream from and in the accumulation of sediments downstream of bouchot lines, as suggested by Sornin (1981).

Although the relationship between the structure of marine benthic soft-sediment communities and the texture of the sediment they inhabit is well-known (Gray 1974, 2002), information on coarser soft-bottom sediments is scarce and thus results from the present

Table 5. Pair-wise test for the interaction between Treatment and Distance (untransformed data, see Table 4) for paired levels of distance factors $(0,1,5$, and $12.5 \mathrm{~m})$. Significant values $(\mathrm{p}<0.05)$ in bold

\begin{tabular}{|ccccc|}
\hline & \multicolumn{2}{c}{ Mussel sites } & \multicolumn{2}{c|}{ Reference sites } \\
Distance level pairs & $t$ & $\mathrm{p}$ (perm) & $t$ & $\mathrm{p}$ (perm) \\
\hline $0 \mathrm{~m} \times 1 \mathrm{~m}$ & 1.442 & 0.0588 & 0.842 & 0.6500 \\
$0 \mathrm{~m} \times 5 \mathrm{~m}$ & 1.513 & $\mathbf{0 . 0 4 3 2}$ & 0.789 & 0.7600 \\
$0 \mathrm{~m} \times 12.5 \mathrm{~m}$ & 1.890 & $\mathbf{0 . 0 0 6 6}$ & 0.840 & 0.6243 \\
$1 \mathrm{~m} \times 5 \mathrm{~m}$ & 0.793 & 0.6911 & 0.813 & 0.7464 \\
$1 \mathrm{~m} \times 12.5 \mathrm{~m}$ & 0.985 & 0.3953 & 1.153 & 0.1982 \\
$5 \mathrm{~m} \times 12.5 \mathrm{~m}$ & 0.909 & 0.4953 & 0.873 & 0.5935 \\
\hline
\end{tabular}


Table 65. Species-specific contribution (\%, raw abundance data) of most abundant species (Goodallia triangularis, Sphaerosyllis bulbosa, $S$. taylori and Cirriformia tentaculata) to total dissimilarity (\%, raw abundance data) of benthic community among distances in mussel sites. In each combination, species are listed in order of decreasing contribution

\begin{tabular}{|c|c|c|}
\hline Distance level pairs & Species & Contribution (\%) \\
\hline $0 \times 1 \mathrm{~m}$ & $\begin{array}{l}\text { Total } \\
\text { G. triangularis } \\
\text { S. bulbosa } \\
\text { S. taylori }\end{array}$ & $\begin{array}{c}72.75 \\
50.7 \\
5.9 \\
4.5\end{array}$ \\
\hline $0 \times 5 \mathrm{~m}$ & $\begin{array}{l}\text { Total } \\
\text { G. triangularis } \\
\text { S. taylori } \\
\text { S. bulbosa }\end{array}$ & $\begin{array}{c}72.51 \\
51.5 \\
6.1 \\
5.8\end{array}$ \\
\hline $0 \times 12.5 \mathrm{~m}$ & $\begin{array}{l}\text { Total } \\
\text { G. triangularis } \\
\text { S. bulbosa } \\
\text { S. taylori }\end{array}$ & $\begin{array}{c}74.32 \\
51.1 \\
5.5 \\
4.7\end{array}$ \\
\hline $1 \times 5 \mathrm{~m}$ & $\begin{array}{l}\text { Total } \\
\text { G. triangularis } \\
\text { S. taylori } \\
\text { S. bulbosa }\end{array}$ & $\begin{array}{c}65.80 \\
44.7 \\
7.7 \\
6.2\end{array}$ \\
\hline $1 \times 12.5 \mathrm{~m}$ & $\begin{array}{l}\text { Total } \\
\text { G. triangularis } \\
\text { C. tentaculata } \\
\text { S. bulbosa }\end{array}$ & $\begin{array}{c}66.24 \\
43.9 \\
6.6 \\
5.9\end{array}$ \\
\hline $5 \times 12.5 \mathrm{~m}$ & $\begin{array}{l}\text { Total } \\
\text { G. triangularis } \\
\text { S. taylori } \\
\text { C. tentaculata }\end{array}$ & $\begin{array}{c}65.05 \\
46.1 \\
8.3 \\
6.7\end{array}$ \\
\hline
\end{tabular}

study provide important new data. In the Chausey Archipelago, benthic communities at mussel sites were mostly related to finer sediment than those at reference sites. However, the low correlation between grain size and benthic community structure suggests that more detailed studies are needed. Sediment grain size is likely not the only factor influencing benthic communities, and the analysis of local hydrodynamic regimes combined with sensitive organic matter analysis and ecological relationships among species are factors that should be considered further to better understand the influence of mussel farming on them. In the Chausey Archipelago, given that mussel farm installations seem to decrease sedimentary particle size but not increase organic enrichment, they may shift benthic communities toward being characterized by fine sedimentassociated species.

Within farms, small-scale variation in macrofaunal communities was coincident with variation in sediments. This suggests that there is a cascading effect of physical structure (bouchots) on hydrodynamics, sediment structure, and benthic infaunal community structure. Moreover, although taxonomic composition was similar at mussel and reference sites, the dominance of some species, such as the bivalve Goodallia triangularis, varied greatly among samples and distances from bouchots. The biology and ecology of this species, commonly found in coarse sediment habitats, are relatively unknown but its high abundance at mussel sites, especially in the vicinity of bouchots, suggests a preference for coarse sediments and probably to local organic enrichment, as suggested by Suroy (2009). Some surface depositfeeder species, such as the polychaete Cirriformia tentaculata, were also abundant close to bouchots, further supporting the notion that there is temporary local enrichment by mussel biodeposits until currents disperse them. Differences observed using multivariate analysis were not detected using either AMBI or univariate community metrics, further supporting the observation made by many studies that multivariate analyses can have greater power to detect effects and can be more informative than univariate methods because they integrate the effects of the abundance of many taxa or other variables into a single entity (Keough \& Quinn 1991, Warwick \& Clarke 1991, Downes et al. 2002). In the present study, multivariate analyses (Fig. 7, Table 4) show that infaunal communities varied among sites within treatment. However, the overall effect of site type and variation within farm sites was also clearly evident. Although the present study may not have documented the entire population of community types in the area, we suggest that the sampled sites do provide a good indication of the range of potential responses.

Callier et al. (2008) also emphasized the importance of choosing the appropriate ecological indicators to determine the influence of shellfish farming on the benthic environment because the a priori choice of ecological indicators may influence the interpretation of results. In the present study, evidence of the effects of the bouchots depends on the indicator used. Except for total abundance, number of taxa and variation in taxonomic distinctness, all other univariate biological indices examined in this study failed to detect significant mussel culturerelated effects on the benthic communities. Diversity indices, such as the Shannon-Wiener index, are widely used but are not necessarily representative of the ecological importance of a community or a change in community structure (Downes et al. 2002). AMBI is based on the sensitivity/tolerance of species with a high AMBI coefficient indicating a poor ecological status. Based on this index, all study sites were classified as being slightly disturbed. Most 


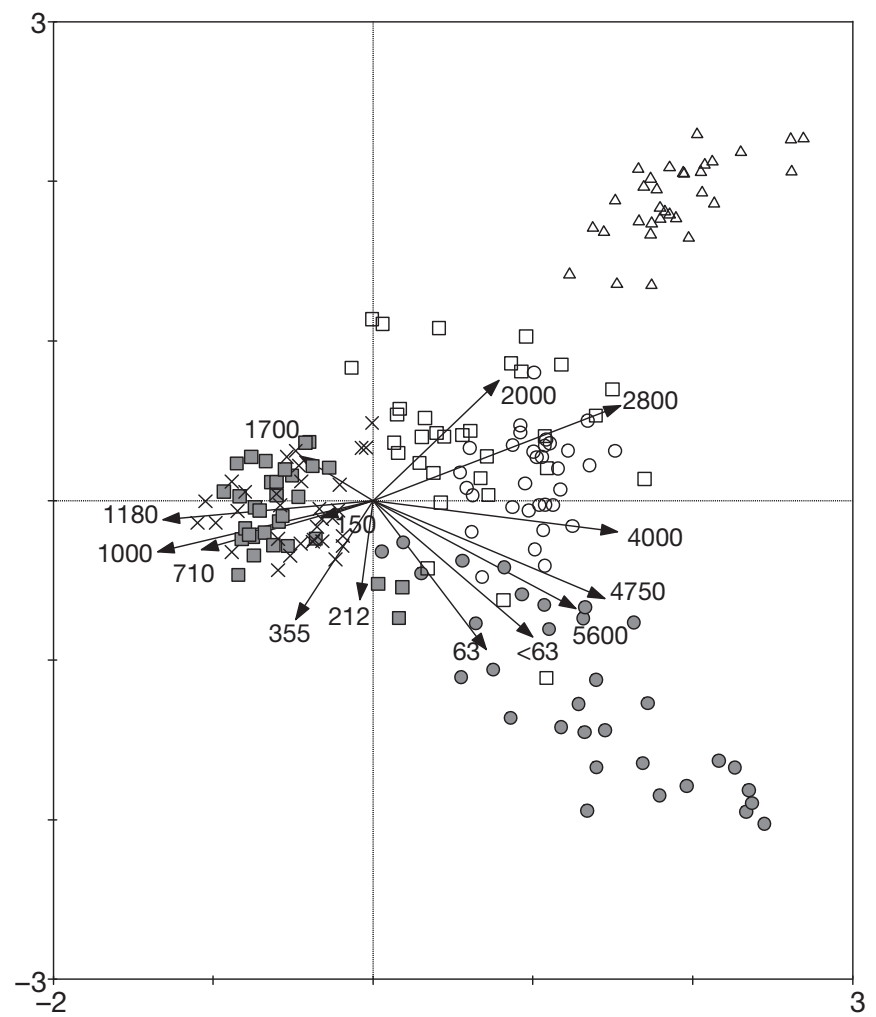

Fig. 8. Canonical correspondence analysis (CCA) biplot of benthic macrofauna at mussel ( $\circ \mathrm{M} 1, \square \mathrm{M} 2, \times \mathrm{M} 3$ ) and reference ( $\circ R 1, \square R 2, \Delta R 3)$ sites with corresponding sediment grain sizes ( $\mu \mathrm{m}$, arrows). CCA calculated for untransformed abundance data and matrix of 14 significant $(p<0.05)$ sediment grain sizes tested

identified taxa were classified into ecological group II (indifferent to pollution), including 5 of the 9 constantly present taxa. According to Borja et al. (2000), a dominance of ecological group II taxa is a characteristic of estuarine communities at sites with organic matter inputs. However, as the Chausey Archipelago is a marine system with little organic input, such interpretation should be treated with caution.

This study also revealed the importance of syllid polychaetes in terms of their abundance and species richness in the Glycymeris glycymeris coarse sediment habitat. In contrast to Goodallia triangularis and the syllid polychaete Sphaerosyllis bulbosa, which were more abundant in the vicinity of the mussel structures, some syllid species, such as Salvatoria swedmarki and Syllis garciai, were almost exclusively present at reference sites. That each syllid species showed specific responses to the presence of mussel farming activities suggests that the group is sensitive to changes due to farming activities and may be useful as species indicators to detect anthropogenic effects of bivalve farming, particularly in the studied habitat. The difficulty of classifying taxa into ecological groups may represent a lack of knowledge about certain groups. For example, all the species of the family Syllidae were classified into the same group. For many years, scientists thought that all syllids were carnivores, but Giangrande et al. (2000) suggested that they are much more variable in their diet than previously assumed and that several species are not carnivorous. This example highlights the fact that the baselines in the elaboration of models were not always right and, consequently, results from those models should be interpreted carefully.

\section{CONCLUSION}

This study showed that culture of mussels on bouchots in the highly dynamic intertidal system of the Chausey Archipelago has a limited effect on the benthic environment as benthic communities varied in terms of structure but less in terms of composition. Effects were evident at 2 spatial scales. At the mesoscale $(\mathrm{km})$, benthic sediments, but not sediment organic matter, and infaunal communities were shown to differ between mussel and reference sites using a variety of metrics. At the small-scale (m), marked spatial structure in sediments and communities was observed within mussel farm sites as numerous sediment and biological metrics varied systematically with distance from bouchots. Given that bouchots are known to impact hydrodynamics at both spatial scales, it is likely that these effects interacted, thus triggering a cascading effect on sediment characteristics which contributed to structuring infaunal communities. Currents disperse mussel biodeposits and limit the deposition of fine sediments and organic matter enrichment, although their temporary presence may contribute to structuring infaunal communities. Chausey is a highly fragmented archipelago (i.e. 9 different habitats sensu Godet 2008) with mussel farms located on Glycymeris glycymeris coarse sediment habitat; thus the benthic effects shown in this study are only representative of this habitat. Further evaluation of the influence of bouchot mussel farms on benthic processes in other types of habitat, such as high energy muddy ones (i.e. Mont SaintMichel Bay, English Channel, France) where most such farming occurs, would be interesting, especially if completed with a detailed description of hydrodynamic processes involved.

Acknowledgements. We thank all the agencies that provided financial support: Conservatoire de l'Espace Littoral 
et des Rivages Lacustres, Syndicat Mixte Espaces Littoraux de la Manche, Direction Régionale de l'Environnement Basse-Normandie, Agence de l'Eau Seine Normandie, and Fond Européen de la Pêche. The authors also acknowledge the support by the Réseau Aquaculture Québec.

\section{LITERATURE CITED}

Anderson MJ (2001) A new method for non-parametric multivariate analysis of variance. Austral Ecol 26:32-46

Anderson MJ, Gorley RN, Clarke KR (2008) PERMANOVA+ for PRIMER: guide to software and statistical methods. PRIMER-E, Plymouth

Black KD (2001) Environmental impacts of aquaculture. Sheffield Academic Press, Sheffield

Blott SJ, Pye K (2001) GRADISTAT: a grain size distribution and statistics package for the analysis of unconsolidated sediment. Earth Surf Process Landf 26:1237-1248

Borja A, Muxika I (2005) Guidelines for the use of AMBI (AZTI's Marine Biotic Index) in the assessment of the benthic ecological quality. Mar Pollut Bull 50:787-789

> Borja A, Franco J, Pérez V (2000) A Marine Biotic Index to establish the ecological quality of soft-bottom benthos within European estuarine and coastal environments. Mar Pollut Bull 40:1100-1114

> Callaway R, Jennings S, Lancaster J, Cotter J (2002) Meshsize matters in epibenthic surveys. J Mar Biol Assoc UK 82:1-8

Callier MD, Weise AM, McKindsey CW, Desrosiers G (2006) Sedimentation rates in a suspended mussel farm (GreatEntry Lagoon, Canada): biodeposit production and dispersion. Mar Ecol Prog Ser 322:129-141

Callier MD, McKindsey CW, Desrosiers G (2008) Evaluation of indicators used to detect mussel farm influence on the benthos: two case studies in the Magdalen Islands, Eastern Canada. Aquaculture 278:77-88

> Callier MD, Richard M, McKindsey CW, Archambault A, Desrosiers G (2009) Responses of benthic macrofauna and biogeochemical fluxes to various levels of mussel biodeposition: an in situ 'benthocosm' experiment. Mar Pollut Bull 58:1544-1553

> Carlsson MS, Glud RN, Petersen JK (2010) Degradation of mussel (Mytilus edulis) fecal pellets released from hanging long-lines upon sinking and after settling at the sediment. Can J Fish Aquat Sci 67:1376-1387

Chamberlain J, Fernandes TF, Read P, Nickell TD, Davies IM (2001) Impacts of biodeposits from suspended mussel (Mytilus edulis L.) culture on the surrounding surficial sediments. ICES J Mar Sci 58:411-416

> Clarke KR (1993) Non-parametric multivariate analyses of changes in community structure. Aust J Ecol 18:117-143

Clarke KR, Gorley RN (2006) PRIMER v6: user manual/ tutorial. PRIMER-E, Plymouth

Clarke KR, Warwick RM (1994) Changes in marine communities: an approach to statistical analysis and interpretation, 1st edn. Natural Environment Research Council, Plymouth Marine Laboratory, Plymouth

Clarke KR, Warwick RM (2001) Change in marine communities: an approach to statistical analysis and interpretation, 2nd edn. PRIMER-E, Plymouth

Clynick BG, McKindsey CW, Archambault P (2008) Distribution and productivity of fish and macroinvertebrates in mussel aquaculture sites in the Magdalen Islands (Québec, Canada). Aquaculture 283:203-210
Couto T, Patrício J, Neto JM, Ceia FR, Franco J, Marques JC (2010) The influence of mesh size in environmental quality assessment of estuarine macrobenthic communities. Ecol Indic 10:1162-1173

> Cranford PJ, Hargrave BT, Doucette LI (2009) Benthic organic enrichment from suspended mussel (Mytilus edulis) culture in Prince Edward Island, Canada. Aquaculture 292:189-196

> Crawford CM, Macleod CKA, Mitchell IM (2003) Effects of shellfish farming on the benthic environment. Aquaculture 224:117-140

Dame RF (1996) Ecology of marine bivalves: an ecosystem approach. CRC Press, Boca Raton, FL

Downes BJ, Barmuta LA, Fairweather PG, Faith DP, Keough MJ, Lake PS, Mapstone BD, Quinn GP (2002) Monitoring ecological impacts: concepts and practice in flowing waters. Cambridge University Press, Cambridge

Fabi G, Manoukian S, Spagnolo A (2009) Impact of an opensea suspended mussel culture on macrobenthic community (Western Adriatic Sea). Aquaculture 289:54-63

Fabiano M, Danovaro R, Olivari E, Misic C (1994) Decomposition of faecal matter and somatic tissue of Mytilus galloprovincialis: changes in organic matter composition and microbial succession. Mar Biol 119:375-384

Giangrande A, Licciano M, Pagliara P (2000) The diversity of diets in Syllidae (Annelida: Polychaeta). Cah Biol Mar 41: $55-65$

Godet L (2008) L'évaluation des besoins de conservation d'un patrimoine naturel littoral marin: l'exemple des estrans meubles de l'archipel de Chausey. PhD thesis, Muséum National d'Histoire Naturelle, Dinard, France

> Grant J, Bacher C, Cranford PJ, Guyondet T, Carreau M (2008) A spatially explicit ecosystem model of seston depletion in dense mussel culture. J Mar Syst 73:155-168

Gray JS (1974) Animal-sediment relationships. Oceanogr Mar Biol Annu Rev 12:223-261

> Gray JS (2002) Species richness of marine soft sediments. Mar Ecol Prog Ser 244:285-297

Gray JS, Elliott M (2009) Ecology of marine sediments: from science to management, 2nd edn. Oxford University Press, New York, NY

> Grebmeier JM, Feder HM, McRoy CP (1989) Pelagicbenthic coupling on the shelf of the northern Bering and Chukchi Seas. II. Benthic community structure. Mar Ecol Prog Ser 51:253-268

> Grebmeier JM, Cooper LW, Feder HM, Sirenko BI (2006) Ecosystem dynamics of the Pacific-influenced Northern Bering and Chukchi Seas in the Amerasian Arctic. Prog Oceanogr 71:331-361

> Hartstein ND, Rowden AA (2004) Effect of biodeposits from mussel culture on macroinvertebrate assemblages at sites of different hydrodynamic regime. Mar Environ Res 57:339-357

Haven DS, Morales-Alamo R (1966) Aspects of biodeposition by oysters and other invertebrate filter feeders. Limnol Oceanogr 11:487-498

Holmer M, Black K, Duarte CM, Marbà N, Karakassis I (2008) Aquaculture in the ecosystem. Springer, New York, NY

> Huettel M, Rusch A (2000) Transport and degradation of phytoplankton in permeable sediment. Limnol Oceanogr 45:534-549

Inglis GJ, Gust N (2003) Potential indirect effects of shellfish culture on the reproductive success of benthic predators. J Appl Ecol 40:1077-1089 
James RJ, Lincoln Smith MP, Fairweather PG (1995) Sieve mesh-size and taxonomic resolution needed to describe natural spatial variation of marine macrofauna. Mar Ecol Prog Ser 118:187-198

> Jumars PA, Nowell ARM (1984) Effects of benthos on sediment transport: difficulties with functional grouping. Cont Shelf Res 3:115-130

Keough MJ, Quinn GP (1991) Causality and the choice of measurements for detecting human impacts in marine environments. Aust J Mar Freshw Res 42:539-554

Lehane C, Davenport J (2004) Ingestion of bivalve larvae by Mytilus edulis: experimental and field demonstrations of larviphagy in farmed blue mussels. Mar Biol 145:101-107

Lehane C, Davenport J (2006) A 15-month study of zooplankton ingestion by farmed mussels (Mytilus edulis) in Bantry Bay, Southwest Ireland. Estuar Coast Shelf Sci 67:645-652

Lepš J, Šmilauer P (2003) Multivariate analysis of ecological data using CANOCO. Cambridge University Press, Cambridge

Martin D, Bertasi F, Colangelo MA, de Vries M and others (2005) Ecological impact of coastal defense structures on sediment and mobile fauna: evaluating and forecasting consequences of unavoidable modifications of native habitats. Coast Eng 52:1027-1051

McKindsey CW, Archambault P, Callier MD, Olivier F (2011) Influence of suspended and off-bottom mussel culture on the sea bottom and benthic habitats: a review. Can J Zool 89:622-646

Miller DC, Sternberg RW (1988) Field measurements of the fluid and sediment-dynamic environment of a benthic deposit feeder. J Mar Res 46:771-796

Nikodic J (1981) Dynamique sédimentaire dans la partie occidentale de la baie du Mont Saint-Michel: influence des installations conchylicoles. PhD thesis, Université de Nantes

Olivier F, Grant C, San Martín G, Archambault P, McKindsey CW (in press) Syllidae (Annelida: Polychaeta: Phyllodocida) from the Chausey Archipelago (English Channel, France), with a description of two new species of the Exogoninae Prosphaerosyllis. Mar Biodiv doi:10.1007/s12526-011-0092-1

Ottman F, Sornin JM (1985) Observations on sediment accumulation as a result of mollusk culture systems in France. In: Chao LN, Kirby-Smith WW (eds) Proc Int Symp Utilization of Coastal Ecosystems: Planning, Pollution and Productivity, 21-27 Nov 1982, Rio Grande, Brazil. Editora da Fundaçao Universidade do Rio Grande, Rio Grande, p 29-337

Editorial responsibility: Jonathan Grant, Halifax, Nova Scotia, Canada
Pearson TH, Rosenberg R (1978) Macrobenthic succession in relation to organic enrichment and pollution of the marine environment. Oceanogr Mar Biol Annu Rev 16: 229-311

Quinn GP, Keough MJ (2002) Experimental design and data analysis for biologists. Cambridge University Press, Cambridge

Retière C (1979) Contribution à la connaissance des peuplements benthiques du Golfe Normanno-Breton. PhD thesis, Université de Rennes

Sarà G, Scilipoti D, Milazzo M, Modica A (2006) Use of stable isotopes to investigate dispersal of waste from fish farms as a function of hydrodynamics. Mar Ecol Prog Ser 313:261-270

SEAMER (2000) Étude d'impact de la restructuration conchylicole en baie du Mont Saint-Michel: etude courantologique et sédimentologique. Rapport d'étude de J.C. Salomon pour la Section Régionale Conchylicole Bretagne Nord

Sornin JM (1981) Processus sédimentaires et biodéposition liés à différents modes de conchyculture: baie de Cancale, anse de l'Aiguillon et bassin de Marennes-Oléron. PhD thesis, Université de Nantes

Sumer BM, Whitehouse RJS, Tørum A (2001) Scour around coastal structures: a summary of recent research. Coast Eng 44:153-190

Suroy M (2009) Impact de la mytiliculture sur la qualité et l'utilisation de la matière organique disponible cas de l'habitat des sédiments grossiers à Glycymeris glycymeris. MSc thesis, Université Pierre et Marie Curie, Paris

ter Braak CJF (1989) CANOCO - an extension of DECORANA to analyze species-environment relationships. Hydrobiologia 184:169-170

ter Braak CJF, Šmilauer P (2002) CANOCO reference manual and CanoDraw for Windows user's guide: software for canonical community ordination (version 4.5). Microcomputer Power, Ithaca

Underwood AJ (1997) Experiments in ecology: their logical design and interpretation using analysis of variance. Cambridge University Press, Cambridge

> Vaucourt C, Bonnot-Courtois C (1992) Dynamique sédimentaire dans les baies de Lancieux et de l'Arguenon (Côte-d'Armor). Norois 153:29-44

- Warwick RM, Clarke KR (1991) A comparison of some methods for analysing changes in benthic community structure. J Mar Biol Assoc UK 71:225-244

Whitehouse R (1998) Scour at marine structures. Thomas Telford, London

Submitted: May 30, 2011; Accepted: November 28, 2011

Proofs received from author(s): January 24, 2012 